\title{
INIBIÇÃO DA COLONIZAÇÃO POR Bradyrhizobium elkanii MAS NÃO POR Glomus intraradices EM SOJA PELO ATIVADOR DE DEFESA VEGETAL BTH ${ }^{1}$
}

\author{
Lúcia Vieira Hoffmann²,4 Elke Jurandy Bran Nogueira Cardoso ${ }^{3 *}$ \\ ${ }^{2}$ Depto. de Biologia Celular e Genética - UFRN/Centro de Biociências - Campus Universitário, BR 101, Lagoa Nova- \\ CEP: 59078-379 - Natal, RN. \\ ${ }_{4}^{3}$ Depto. de Solos e Nutrição de Plantas - USP/ESALQ, C.P. 9 - CEP:13418-900 - Piracicaba, SP. \\ ${ }^{4}$ Bolsista CAPES. \\ *Autor correspondente <ejbncard@carpa.ciagri.usp.br>
}

RESUMO: O produto BTH controla doenças através da ativação dos mecanismos de resistência de plantas, cujo modo de ação tem sido caracterizado através da identificação de genes ou enzimas ativados durante esta reação. Os mesmos genes e enzimas podem ser ativados como parte da reação das plantas à colonização por microssimbiontes mutualistas. Então, a aplicação de BTH pode inibir também essas simbioses. Um experimento foi conduzido para verificar se BTH tem efeito sobre a colonização de raízes de soja pelos microssimbiontes Glomus intraradices e Bradyrhizobium elkanii. Plantas controle ou inoculadas com o fungo micorrízico ou rizóbio foram tratadas com $20 \mathrm{~mL}$ de BTH $25 \mathrm{mg} \mathrm{L}^{-1}$ por meio da aplicação em sementes, via radicular ou via foliar. As plantas que receberam aplicação radicular de BTH tiveram desenvolvimento vegetativo reduzido. A colonização de raízes por $B$. elkanii foi menor nas plantas que receberam aplicação de BTH via radicular do que naquelas não tratadas ou tratadas por via foliar apenas. A colonização de raízes de soja por G. intraradices não foi afetada por BTH em quaisquer dos modos de aplicação. A aplicação radicular de BTH deve ser evitada na cultura da soja. Não há indício de restrição de aplicação foliar do produto.

Palavras-chave: micorriza, rizóbio, resistência sistêmica adquirida

\section{INHIBITION OF THE COLONIZATION BY Bradyrhizobium elkanii BUT NOT BY Glomus intraradices OF SOYBEAN BY THE PROTECTION COMPOUND BTH}

\begin{abstract}
The compound BTH controls plant diseases activating a plant disease resistance response, which can be characterised by identifying genes or enzymes activated during this reaction. Some genes or enzymes can be activated during plant reaction to colonization pathways by microsymbionts. Therefore, the application of products that activate protection mechanisms like BTH, could also inhibit mutualistic symbioses. An experiment was carried out to establish the effect of BTH on soybean colonization by Bradyrhizobium elkanii and Glomus intraradices. Control plants or plants inoculated with rhizobium or mycorrhizal fungus were treated with BTH (20 mL of a $25 \mathrm{mg} \mathrm{L}^{-1}$ solution) via seeds, roots or leaves. BTH reduced plant growth when applied to roots. Roots were colonized at a lower rate by $B$. elkanii in plants to which BTH was applied via roots, when compared to control plants or plants treated via leaves. BTH treatment had no effect on the colonization of soybean roots by Glomus intraradices. It is suggested to avoid BTH application to soybean roots, although there is no restriction to the foliar treatment.

Key words: mycorrhiza, rhizobium, systemic acquired resistance
\end{abstract}

\section{INTRODUÇÃO}

É praticamente inexplorado comercialmente o controle de doenças de plantas por meio do estímulo à ativação de seus mecanismos de defesa. Esta estratégia deve ser ampliada pelo composto BTH, também conhecido pelo nome comercial de Bion, que quando aplicado em Arabidopsis thaliana (Lawton et al., 1996) ou tabaco (Friedrich et al., 1996), induz as plantas a sintetizar proteínas que podem restringir a colonização por patógenos e que caracterizam a reação de defesa conhecida como "resistência sistêmica adquirida". Nestas espécies, bem como em trigo (Görlach et al., 1996), feijão
(Siegrist et al., 1997) e tomate (Benhamou \& Bélanger, 1998), a aplicação do produto reduz a colonização por fungos ou bactérias fitopatogênicos.

Como a resistência sistêmica adquirida é de natureza inespecífica, ou seja, é eficaz contra uma gama relativamente ampla de patógenos (Ryals et al., 1996), ela pode ser inibitória também para microrganismos simbiontes mutualísticos.

Micorrizas e a associação de rizóbios com plantas leguminosas são simbioses mutualísticas de grande importância econômica. Fungos micorrízicos arbusculares associam-se a mais do que $80 \%$ das famílias botânicas. Suas hifas podem ser comparadas a 
prolongamentos das raízes da planta hospedeira, porque absorvem água e nutrientes fornecidos à planta através dos arbúsculos, ramificações formadas pelas hifas internas às células do hospedeiro. O nutriente economicamente mais importante obtido é o fósforo, devido à sua escassez e baixa mobilidade no solo (Silveira, 1992). Rizóbios são bactérias que, quando em associação simbiótica com plantas da família Fabaceae, antiga Leguminosae, transformam o nitrogênio atmosférico em amônio, tornando-o disponível para a planta hospedeira (Freire, 1992). Em soja, todo o nitrogênio necessário pode ser obtido através da fixação do $\mathrm{N}_{2}$ atmosférico por Bradyrhizobium japonicum ou por B. elkanii.

Dada a importância das simbioses, a redução de sua eficiência pela aplicação de produtos que ativam os mecanismos das plantas de proteção às doenças, como BTH, pode resultar em danos de relevância econômica.

O objetivo deste trabalho foi analisar o efeito da aplicação de BTH sobre a associação de plantas de soja com os microssimbiontes Bradyrhizobium elkanii e Glomus intraradices.

\section{MATERIAL E MÉTODOS}

\section{Delineamento experimental}

Os tratamentos foram organizados em esquema fatorial $5 \times 3$, sendo: quatro formas de aplicação de BTH e um controle sem o ativador, associados a B. elkanii, G. intraradices e um controle não inoculado. O delineamento foi inteiramente ao acaso, com seis repetições por tratamento.

\section{Preparo do substrato}

O experimento foi conduzido em casa de vegetação do Departamento de Solos e Nutrição de Plantas na ESALQ/USP, com temperatura controlada e mantida no intervalo entre 18 e $30^{\circ} \mathrm{C}$.

Vasos contendo $3 \mathrm{~kg}$ de solo de baixa fertilidade (Neossolo Quartzarênico) misturado a areia de rio na proporção $3: 1(\mathrm{v} / \mathrm{v})$ foram autoclavados a $121^{\circ} \mathrm{C}$ por 2 horas e adubados com $20 \mathrm{mg} \mathrm{dm}^{-3}$ de $\mathrm{P}$ (na forma de $\mathrm{KH}_{2} \mathrm{PO}_{4}$ ); $60 \mathrm{mg} \mathrm{dm}^{-3}$ de N (na forma de $\left(\mathrm{NH}_{4}\right)_{2} \mathrm{SO}_{4}$ ); 0,5 $\mathrm{mg} \mathrm{dm}^{-3}$ de $\mathrm{B}$ (na forma de $\mathrm{H}_{3} \mathrm{BO}_{3}$ ), $0,5 \mathrm{mg} \mathrm{dm}^{-3}$ de $\mathrm{Cu}$ (na forma de $\mathrm{CuSO}_{4} \cdot 5 \mathrm{H}_{2} \mathrm{O}$ ), $0,3 \mathrm{mg} \mathrm{dm}{ }^{-3}$ de $\mathrm{Zn}$ (na forma de $\mathrm{ZnSO}_{4} 7 \mathrm{H}_{2} \mathrm{O}$ ) e $0,05 \mathrm{mg} \mathrm{dm}^{-3}$ de Mo (na forma de $\mathrm{Na}_{2} \mathrm{MoO}_{4} .2 \mathrm{H}_{2} \mathrm{O}$ ).

\section{Tratamento químico}

O éster 2-metil benzol $(1,2,3)$ tiadiazole-7carbônico (BTH) foi fornecido pela Novartis na forma do produto comercial Bion $500 \mathrm{WG}^{\circledR}$, um granulado dispersível contendo $50 \%$ do ingrediente ativo, cujo peso molar é $210,3 \mathrm{~g} \mathrm{~mol}^{-1}$.

Foi preparada solução do produto na concentração de $25 \mathrm{mg} \mathrm{L}^{-1}$, e aplicados $20 \mathrm{~mL}$, em diferentes formas, totalizando $500 \mu \mathrm{g}$ por planta.
Os tratamentos em relação a BTH foram: i) controle (sem aplicação de BTH); ii) aplicação em sementes, que foram incubadas, por 5 horas, em placa de Petri, em solução de BTH, à temperatura ambiente. A solução foi colocada de forma a cobrir cerca de $50 \%$ do volume total da semente. As sementes dos demais tratamentos foram incubadas pelo mesmo período, mas em água; iii) aplicação de BTH via radicular, no quarto dia após o plantio; iv) aplicação de BTH via radicular no $18^{\circ}$ e $19^{\circ}$ dias após o plantio, quando as plantas apresentavam o segundo trifólio aberto, e v) aplicação de BTH via foliar, no $18^{\circ}$ e $19^{\circ}$ dias após o plantio. A aplicação foliar do produto foi feita com pulverizador manual. Como a área foliar era pequena para reter toda a solução neste estádio de desenvolvimento, a aplicação de BTH foi feita em quatro pulverizações de $5 \mathrm{~mL}$, com intervalos suficientes para permitir a absorção do produto antes de nova aplicação. Para evitar que respingos das folhas caíssem no solo e fossem simultaneamente absorvidos por via radicular, durante a aplicação foram colocados plásticos cobrindo o substrato, mantidos até o final da absorção.

\section{Inoculação}

Em relação aos microssimbiontes, os tratamentos foram: i) controle (plantas não inoculadas); ii) plantas inoculadas com B. elkanii estirpe SEMIA 587, no terceiro dia após o plantio e iii) plantas inoculadas com G. intraradices, no momento do plantio.

Solo contendo hifas e esporos de Glomus intraradices Schenck \& Smith foi coletado em vasos de plantas de Brachiaria decumbens Stapf mantidas em casa de vegetação, homogeneizado manualmente e, com uma pá medidora com capacidade de $25 \mathrm{~mL}$, colocado nos vasos, em região próxima à semente.

A bactéria Bradyrhizobium elkanii cresceu em meio de cultura contendo $10 \mathrm{~g} \mathrm{~L}^{-1}$ de manitol, $0,5 \mathrm{~g} \mathrm{~L}^{-1}$ de $\mathrm{K}_{2} \mathrm{HPO}_{4}, 0,8 \mathrm{~g} \mathrm{~L}^{-1}$ de $\mathrm{MgSO}_{4} \cdot 7 \mathrm{H}_{2} \mathrm{O}, 0,2 \mathrm{~g} \mathrm{~L}^{-1} \mathrm{NaCl}, 0,01$ $\mathrm{g} \mathrm{L}^{-1}$ de $\mathrm{FeCl}_{3} \cdot 6 \mathrm{H}_{2} \mathrm{O}$, acrescido de $10 \mathrm{mg} \mathrm{L}^{-1}$ de azul de bromotimol, sob agitação orbital a $28^{\circ} \mathrm{C}$, por quatro dias. Para a inoculação, $4 \mathrm{~mL}$ da cultura bacteriana foram colocados em cada vaso, em região próxima à semente, no terceiro dia após o plantio.

\section{Coleta dos resultados e análise estatística}

A coleta do material vegetal foi feita no $47^{\circ}$ dia após o plantio. Os nódulos de cada planta foram retirados e contados. As partes aéreas, as raízes e os nódulos foram colocados em estufa com circulação de ar forçada, a $65^{\circ} \mathrm{C}$, por 48 horas, e determinado o peso de matéria seca.

Para a avaliação da colonização por $G$. intraradices, as raízes, secas em estufa, foram colocadas em água por 48 horas para re-hidratação e, a seguir, transferidas para solução fixadora contendo etanol, ácido acético, formaldeído $37 \%$ e água, na proporção $2: 0,1$; $0,5: 4(\mathrm{v} / \mathrm{v} / \mathrm{v} / \mathrm{v})$. Foi feita coloração das raízes com azul de tripano a $0,05 \%$ (Phillips \& Hayman, 1970) e 
observadas sob lupa, em placa de Petri que possui, no fundo, linhas quadriculadas. A porcentagem de colonização foi calculada dividindo-se o número de vezes em que as estruturas do fungo (hifas, arbúsculos ou vesículas) estão presentes nos pontos em que as raízes cruzam as linhas pelo número total de observações (Ambler \& Young, 1977).

Os pesos de matéria seca de parte aérea e raiz, o número e matéria seca de nódulos e a porcentagem de raízes colonizadas por fungo micorrízico foram submetidos à análise estatística para comparação das médias. Procedeu-se, primeiro, a análise de variância e depois ao teste de Duncan para comparações múltiplas.

\section{RESULTADOS E DISCUSSÃO}

\section{Efeito dos microssimbiontes e de BTH no desenvolvimento vegetativo da soja}

A inoculação com microrganismos $(P<0,01)$ e o uso de tratamentos com BTH $(P<0,05)$ tiveram efeito sobre os pesos médios de matéria seca de parte aérea e de raiz (TABELA 1). Não existiu efeito da interação entre o modo de aplicação de BTH e presença ou espécie de microrganismo.

A inoculação com $G$. intraradices estimulou o desenvolvimento das plantas, medido pelo aumento do peso médio de matéria seca da parte aérea ou da raiz, segundo o teste de Duncan, a $5 \%$, como mostra a TABELA 1.

A aplicação de $20 \mathrm{~mL}$ de solução de BTH a 25 $\mathrm{mg} \mathrm{L}^{-1}$ por via radicular, aos 4 dias após o plantio, reduziu o desenvolvimento vegetativo da soja, estimado pelos pesos de matéria seca de parte aérea e raiz, segundo o teste de Duncan, a 5\%. A redução dos pesos de matéria seca de parte aérea e raiz foi menos expressiva nas plantas que receberam aplicação radicular aos 18 dias, que não diferiram significativamente do controle. Isto pode ser explicado por diferença fisiológica entre plantas de diferentes fases de desenvolvimento, seja na absorção ou no efeito de BTH, ou por abrandamento do efeito do produto devido à sua melhor distribuição em decorrência do tamanho maior da planta.

A redução de desenvolvimento vegetativo não foi observada quando a aplicação do produto foi via foliar. A deformação de folhas, relatada em feijoeiro devido à aplicação foliar de BTH (Siegrist et al., 1997), não foi observada em soja. Assim, a aplicação de BTH, via radicular, pode ter efeito fitotóxico, mas não a aplicação foliar, na dose testada.

\section{Efeito de BTH na colonização de raízes de soja por G. intraradices}

As percentagens de raízes colonizadas por $G$. intraradices (TABELA 2) não foram afetadas pela aplicação de BTH na dose testada, segundo o teste $F$ $(p=0,69)$. Portanto, o experimento não indica que deva haver restrição da aplicação do produto, via foliar ou radicular, devido a prejuízo no desenvolvimento da simbiose da planta com o fungo micorrízico arbuscular.

Se existe uma reação de defesa, ao nível radicular, induzida pelo $\mathrm{BTH}$, esta não teve efeito sobre o desenvolvimento da micorriza. Em uma fase breve, no início do processo de colonização por fungos micorrízicos arbusculares, as plantas reagem com aumento de expressão de enzimas relacionadas à defesa contra patógenos, que, com o progresso da interação simbiótica, passam a ser expressas em um nível inferior ao período anterior à infecção (Gianinazzi-Pearson, 1996). Este processo pode ser ativo também na inibição da reação de defesa estimulada pelo BTH. Assim, em tabaco, a aplicação radicular de BTH $50 \mathrm{mg} \mathrm{L}^{-1}$ provocou, na raiz, aumento de atividade de uma isoforma de quitinase básica, a mesma cuja atividade é inibida, durante a colonização pelo fungo G. intraradices. Quando plantas micorrizadas foram tratadas com BTH por via radicular, a atividade da isoforma permaneceu abaixo da verificada nos controles não inoculados e não tratados, mostrando que a interação com o fungo pode inibir o efeito do produto (David et al., 1998). Portanto, a interação simbiótica pode ter capacidade de inibir a reação de defesa da planta.

TABELA 1 - Peso de matéria seca da parte aérea e raiz de soja, tratada com BTH $25 \mathrm{mg} \mathrm{L}^{-1}$ e submetida à inoculação de microrganismos simbiontes, aos 47 dias após o plantio.

\begin{tabular}{|c|c|c|c|c|c|c|c|c|}
\hline \multirow{3}{*}{$\begin{array}{l}\text { Presença / ausência de BTH e } \\
\text { modo de aplicação }\end{array}$} & \multicolumn{8}{|c|}{ Presença ou ausência e espécie de microrganismo } \\
\hline & \multicolumn{2}{|c|}{ Sem inoculação } & \multicolumn{2}{|c|}{ G. intraradices } & \multicolumn{2}{|c|}{ B. elkanii } & \multicolumn{2}{|c|}{ Média } \\
\hline & MSPA & MSR & MSPA & MSR & MSPA & MSR & MSPA & MSR \\
\hline & 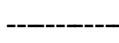 & 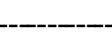 & $\cdots$ & - & g-- & -1 & 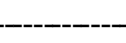 & 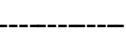 \\
\hline Controle & 3,48 & 1,32 & 6,22 & 1,63 & 4,72 & 1,30 & $4,81 \mathrm{a}$ & $1,42 a$ \\
\hline em semente & 3,32 & 1,08 & 6,10 & 1,67 & 3,80 & 0,97 & $4,41 \mathrm{ab}$ & $1,24 a b$ \\
\hline via raiz, 4 dias & 2,60 & 0,67 & 4,87 & 1,32 & 2,52 & 0,67 & $3,33 \mathrm{~b}$ & $0,88 b$ \\
\hline via folha, 18 dias & 2,82 & 0,88 & 6,73 & 1,97 & 4,92 & 1,17 & $4,82 \mathrm{a}$ & $1,34 \mathrm{a}$ \\
\hline via raiz, 18 dias & 2,90 & 0,93 & 6,07 & 1,63 & 3,00 & 0,82 & $3,99 \mathrm{ab}$ & $1,13 a b$ \\
\hline Média & $3,02 \mathrm{c}$ & $0,98 \mathrm{~b}$ & $6,00 a$ & $1,64 a$ & $3,79 \mathrm{~b}$ & $0,98 \mathrm{~b}$ & 4,27 & 1,20 \\
\hline
\end{tabular}

MSPA = Matéria seca da parte aérea; MSR = Matéria seca de raízes.

Nota: Para cada variável, letras diferentes indicam que as médias são diferentes, segundo o teste de Duncan a $5 \%$. 


\section{Efeito de BTH na colonização de raízes de soja por B. elkanii}

A aplicação de BTH teve efeito sobre a intensidade de colonização de raízes de soja por $B$. elkanii, medida pelo número de nódulos por planta $(p=$ $0,01)$ e pela matéria seca de nódulos $(p=0,04)$, segundo os testes $F$ (TABELA 3 ). As plantas tratadas com o produto aos quatro ou dezoito dias do plantio via radicular apresentaram menor número de nódulos, comparativamente ao controle ou às plantas que receberam BTH via foliar, segundo o teste de Duncan, ao nível de $5 \%$ de significância. A matéria seca dos nódulos foi menor nas plantas que receberam aplicação de BTH via radicular, aos 4 ou 18 dias do plantio, do que naquelas que não foram tratadas, ou foram tratadas via foliar.

Portanto, a aplicação radicular inibiu a intensidade de colonização por $B$. elkanii, restringindo a viabilidade da aplicação comercial do produto na cultura da soja nesta forma de aplicação. Para outras leguminosas, deve ser avaliado o efeito da aplicação sobre a interação com rizóbios, antes de se fazer recomendação de aplicação do produto. O composto BTH tem efeito na colonização de plantas por patógenos (Lawton et al., 1996) e a inespecificidade dos mecanismos envolvidos pode levar também à inibição de colonização por microssimbiontes mutualísticos. A planta coordena o processo de infecção por rizóbios, mas, ao

TABELA 2 - Aplicação de BTH e média da percentagem de colonização de raízes de soja por $G$. intraradices, aos 47 dias após o plantio.

\begin{tabular}{|c|c|c|}
\hline $\begin{array}{l}\text { Presença/ausência de } \\
\text { BTH e modo de } \\
\text { aplicação }\end{array}$ & \multicolumn{2}{|c|}{ Colonização média (\%) } \\
\hline Controle & \multicolumn{2}{|c|}{$62 \mathrm{a}$} \\
\hline em semente & \multicolumn{2}{|c|}{$54 a$} \\
\hline radicular, 4 dias & \multicolumn{2}{|c|}{58 a } \\
\hline foliar, 18 dias & \multicolumn{2}{|c|}{$49 a$} \\
\hline radicular 18 dias & \multicolumn{2}{|c|}{$52 \mathrm{a}$} \\
\hline \multicolumn{3}{|c|}{$\begin{array}{l}\text { Nota: letras iguais indicam que o teste de Duncan não detectol } \\
\text { diferenças entre médias, a } 5 \% \text {. }\end{array}$} \\
\hline \multicolumn{3}{|c|}{$\begin{array}{r}\text { TABELA } 3 \text { - Aplicação de BTH e colonização de raízes de } \\
\text { soja por } B \text {. elkanii, aos } 47 \text { dias após o plantio }\end{array}$} \\
\hline \multirow[t]{2}{*}{$\begin{array}{l}\text { Presença/ausência } \\
\text { de BTH e modo de } \\
\text { aplicação }\end{array}$} & $\begin{array}{l}\text { Número de } \\
\text { nódulos }\end{array}$ & $\begin{array}{l}\text { Matéria seca } \\
\text { de nódulos }\end{array}$ \\
\hline & & ----- mg ---- \\
\hline Controle & $123,5 \mathrm{a}$ & $92,2 \mathrm{a}$ \\
\hline em semente & $78,7 \mathrm{abc}$ & $65,2 a b$ \\
\hline Radicular, 4 dias & $46,7 \mathrm{bc}$ & $33,7 \mathrm{~b}$ \\
\hline foliar, 18 dias & $96,3 a b$ & 93,0 a \\
\hline Radicular, 18 dias & $32,2 \mathrm{c}$ & $24,0 \mathrm{~b}$ \\
\hline
\end{tabular}

Nota: letras diferentes indicam que as médias diferem entre si segundo o teste de Duncan a $5 \%$. mesmo tempo, a restrição de colonização é um mecanismo ativo neste processo. Isto fica demonstrado em plantas leguminosas mutantes que não regulam o número de nódulos, onde ocorre o fenótipo de supernodulação. As partes aéreas destes mutantes apresentam crescimento reduzido, demonstrando que na supernodulação o rizóbio é um parasita (revisto por Pawlowski \& Bisseling, 1996) e que há necessidade de um mecanismo da planta em restringir a colonização.

$\mathrm{O}$ tratamento de sementes com BTH tendeu a reduzir a colonização por $B$. elkanii, embora não tenha se diferenciado do controle, segundo o teste de Duncan. A importância do tratamento de sementes deve-se à maior viabilidade econômica de aplicação em culturas comerciais, além de que os microrganismos estudados têm persistência no solo e o estímulo com o produto pode ser requerido anteriormente à inoculação, para que haja efeito de proteção. Siegrist et al. (1997) mostraram que o tratamento de sementes com BTH induziu, em feijoeiro, resistência a fungos e bactérias fitopatogênicos.

Nas plantas que receberam aplicação de BTH, na dose de $500 \mu \mathrm{g}$ por planta, via foliar, não houve redução do número ou peso de matéria seca de nódulos por planta em relação ao tratamento controle. Também não houve redução de crescimento das plantas, como houve no caso da aplicação radicular. Em conjunto, os resultados mostram que BTH somente mostrou efeito inibitório quando aplicado via radicular e que as diferenças observadas entre plantas que receberam o produto via foliar ou via radicular poderiam ser devidas à não translocação de sinal da parte aérea para a raiz.

\section{CONCLUSÕES}

A aplicação de BTH em raízes de soja deve ser evitada, uma vez que existe a possibilidade de inibição do desenvolvimento da simbiose mutualística com $B$. elkanii. Os resultados não indicam restrição da viabilidade de aplicação foliar do produto.

\section{AGRADECIMENTOS}

Aos técnicos de laboratório Denise de Lourdes Colombo Mescolotti e Luís Fernando Baldesin pela boa vontade e ajuda no preparo dos vasos e colheita do experimento.

\section{REFERÊNCIAS BIBLIOGRÁFICAS}

AMBLER, J.R.; YOUNG, J.L. Techniques for determining root length infected by vesicular-arbuscular mycorrhizae. Soil Science Society of America Journal, v.41, p.551-554, 1977. BENHAMOU, N.; BÉLANGER, R.R. Benzothiadiazole-mediated induced resistance to Fusarium oxysporum f. sp. Radicislycopersici in tomato. Plant Physiology, v.118, p.1203-1212, 1998. 
DAVID, R.; ITZHAKI, H.; GINZBERG, I.; GAFNI, Y.; GALILI, G.; KAPULNIK, Y. Suppression of tobacco basic chitinase gene expression in response to colonization by arbuscular mycorrhizal fungus Glomus intraradices. Molecular Plant Microbe Interactions, v.11, p.489-497, 1998.

FREIRE, J.R.J. Fixação do nitrogênio pela simbiose rizóbio/ leguminosas. In: CARDOSO, E.J.B.N.; TSAI, S.M.; NEVES, M.C.P. Microbiologia do solo. Campinas: SBCS, 1992. cap.20, p.281-296.

FRIEDRICH, L.; LAWTON, K.; RUESS, W.; MASNER, P.; SPECKER, N.; RELLA, M.G.; MEIER, B.; DINCHER, S.; STAUB, T.; UKNES, S.; MÉTRAUX, J.; KESSMANN, H.; RYALS, J. A benzothiadiazole derivate induces systemic acquired resistance in tobacco. The Plant Journal, v.10, p.6170, 1996.

GIANINAZZI-PEARSON, V. Plant cell responses to arbuscular mycorrhizal fungi: getting the roots of symbiosis. The Plant Cell, v.8, p.1871-1883, 1996.

GÖRLACH, J.; VOLRATH, S.; KNAUF-BEITER, G.; HENGY, G.; BECKHOVE, U.; KOGEL, K.; OOSTENDORP, M.; STAUB, T.; WARD, E.; KESSMANN, H.; RYALS, J. Benzothiadiazole, a novel class of inducers of systemic acquired resistance, activates gene expression and disease resistance in wheat. The Plant Cell, v.8, p.629-643, 1996.
LAWTON, K.A.; FRIEDRICH, L.; HUNT, M.; WEYMANN, K.; DELANEY, T.; KESSMANN, H.; STAUB, T.; RYALS, J. Benzothiadiazole induces disease resistance in Arabidopsis by activation of the systemic acquired resistance signal transdution pathway. The Plant Journal, v.10, p.71-82, 1996.

PAWLOWSKI, K.; BISSELING, T. Rhizobial and actinorhizal symbioses: what are shared features. The Plant Cell, v.8, p.1899-1913, 1996.

PHILLIPS, J.M.; HAYMAN, D.S. Improved procedures for clearing roots and staining parasitic and vesicular-arbuscular mycorrhizal fungi for rapid assessment of infection. Transactions of the British Mycological Society, v.55, p.158-161, 1970.

RYALS, J.A; NEUENSHWANDER, U.H.; WILLITS, M.G.; MOLINA, A.; STEINER, H.; HUNT, M. Systemic acquired resistance. The Plant Cell, v.8, p.1809-1819, 1996.

SIEGRIST, L.; GLENEWINKEL, D.; KOLLE, C.; SCHMIDTKE, $M$. Chemically induced resistance in green bean against bacterial and fungal pathogens. Journal of Plant Disease and Protection, v.104, p.599-610, 1997

SILVEIRA, A.P.D. Micorrizas. In: CARDOSO, E.J.B.N.; TSAI, S.M.; NEVES, M.C.P. Microbiologia do solo. Campinas: SBCS, 1992. cap.19, p.257-282.

$\overline{\text { Recebido em } 30.10 .00}$ 